\title{
A BUSCA DA HISTORICIDADE DA VIDA NA PESQUISA SOBRE O ENSINO SECUNDÁRIO BRASILEIRO: ENTRE MEMÓRIA E HISTÓRIA ORAL ${ }^{1}$
}

\author{
Décio Gatti Júnior ${ }^{2}$ \\ Giseli Cristina do Vale Gatti ${ }^{3}$
}

\section{RESUMO}

Trata-se de uma reflexão teórico-metodológica a respeito da pesquisa em História da Educação, com ênfase sobre o ensino secundário brasileiro, por meio da observação das relações entre finalidades ideais e práticas educativas, buscando a forma como os indivíduos compreenderam e agiram no mundo histórico-educativo que habitaram. Metodologicamente, o recurso a História Oral pode contribuir para dar vida a acontecimentos que por vezes são relatados nos documentos manuscritos, escritos e iconográficos que restam do passado, com o exame de questões que transcendem as regras determinadas pelos poderes constituídos, mas que estão contidas na forma particular como docentes e discentes efetivaram suas práticas, sua vida cotidiana, servindo-se dos recursos próprios e dos interesses que possuíam a época. Imagens do lugar são sempre úteis e ajudam a nos colocar na cena, ainda que as escolhas daquilo que se registra sejam quase sempre administradas pelo poder estabelecido e pelos interesses de propaganda. Todavia, ao cotejar documentos que restaram do passado e imagens que se produziram naquela época, com aquilo que os indivíduos puderam memorizar, por meio da recolha de valiosos depoimentos, é algo que poderá possibilitar uma análise mais abrangente, na direção de cotejar às finalidades estabelecidas à realidade das práticas escolares vivenciadas, neste caso particular, em relação ao ensino secundário brasileiro.

Palavras-chave: Historiografia, Memória, História Oral.

\section{THE SEARCH FOR HISTORICITY OF LIFE IN RESEARCH ON BRAZILIAN SECONDARY EDUCATION: BETWEEN MEMORY AND ORAL HISTORY}

\begin{abstract}
This paper is a theoretical-methodological reflection in regard to research in History of Education, with emphasis on Brazilian secondary education by means of observation of the relations between ideal purposes and educational practices, seeking the way that individuals understand and act in the historical educational world they inhabit. Methodologically, making use of Oral History may contribute to giving life to events which at times are related in manuscripts, written documents, and iconographic documents that remain from the past, with the examination of questions that transcend the rules determined by constituted powers but that are contained in the particular manner that teachers and students carried out their practices and their daily life, making use of their own resources and of the interests they had at that time. Images of the place are always useful and help to place us in the scene, even if the choices of that which is registered are almost always administrated by the established power and by advertising interests. However, upon comparing documents that remained from the past and images that were produced at that time with that which individuals were able to memorize through gathering valuable testimonies is something that may allow a more encompassing analysis in the direction of comparing the established purposes with the reality of experienced school practices, in this particular case, in relation to Brazilian secondary education.
\end{abstract}

Keywords: Historiography, Memory, Oral History. 
A presente reflexão aborda questões teóricas e metodológicas da pesquisa em História da Educação, notadamente, sobre o ensino secundário brasileiro, com a observação das relações entre finalidades e práticas educativas, sobretudo, da forma como os indivíduos compreenderam e agiram no mundo histórico-educativo que habitaram em determinado lugar e época, para o que se procura demonstrar o papel importante que o recurso às memórias dos indivíduos, por meio dos aportes da História Oral, podem ter na compreensão dos acontecimentos e dos processos histórico-educacionais.

\section{Em busca da historicidade da vida}

Comecemos esse empreendimento por um lugar não muito provável, mas que pareceu útil aos propósitos desse texto, a saber: os mitos fundadores do "homem novo". Em análises bastante interessantes, Dominique Julia (1993) e José Carlos Reis (2006) tomam o ponto central que assinala as profundas diferenças entre a abordagem de Wilhelm Dilthey (1833-1911) e de Émile Durkheim (1858-1917) no quadro mais geral da historiografia da educação e, coincidentemente, a partir do que Julia chamou de mito fundador, qual seja: a Revolução Francesa, à qual, por justiça, parece importante, relacionar à Independência dos Estados Unidos, de 1776.

Essas diferenças de posicionamento impactam, por exemplo, nos discursos contidos na historiografia educacional, sobretudo, conforme afirma Julia, na França, em que a

[...] a história da educação transportou, por muito mais tempo do que em qualquer outro país europeu, uma carga ideológica muito forte. O motivo desse sobreinvestimento deve ser procurado no papel que, em todo o curso do século XIX, a Revolução Francesa - que se pensou e quis ser inteiramente projeto pedagógico - não parou de desempenhar nas consciências, suscitando entre seus partidários e seus adversários paixões contraditórias. O litígio escolar que ali encontrou sua origem não poderia deixar de repercutir fortemente no campo da historiografia [...] com relação ao mito fundador que pode sobrepujar a análise científica (Grifos meus, JULIA, 1993, p. 264-5).

Assim, o século XIX e, por consequência, os debates teóricos no processo de constituição das ciências humanas encontrariam nesses grandes acontecimentos um ponto de ruptura e de divergência, no qual, duas posições se contrapuseram.

De um lado, aqueles que examinam o passado como algo que deve ser superado pela "nova sociedade" e pelo "novo homem": autônomo, capaz do autogoverno, da liberdade e da felicidade, ao qual interessa a relação do presente com o futuro, com a certeza de que a articulação entre ciência, ação social informada e gestão estatal conduzirá necessariamente ao progresso e ao bem-estar geral. Nesse quadro, é possível relacionar o que afirmavam os líderes revolucionários na França com as ideias matriciais de Descartes, pois que a semelhança dele decretavam que

[...] todas as crenças anteriores, todas as ideiais herdadas da família, da nação, ou transmitidas desde a infância pelas "autoridades" como as dos mestres ou da Igreja, por exemplo, devem ser postas em dúvida, criticadas, examinadas com toda liberdade por um sujeito que se posiciona como soberano autônomo, capaz de decidir sozinho sobre o que é verdadeiro ou não, da mesma forma os revolucionários franceses decretam que é preciso acabar com todas as heranças do Antigo Regime. Como diz um deles - [...] Saint-Etienne - por meio de uma fórmula 
perfeitamente "cartesiana" e que também fará época, a Revolução pode ser resumida numa frase: 'Nossa história não é nosso código' (Grifos meus, Ferry, 2007, p. 161-2).

De outro lado, aqueles que advogam que a mudança social, ainda que necessária, deva ser gradual, adequada ao espírito de um povo, de uma nação e que valorize esse passado nacional, como ponto de partida da ação social, rumo à melhoria das condições de vida, mas de uma vida desejada a partir de um processo de vivência a ser compreendido pelas ciências do espírito, dado que não há nenhuma certeza que o futuro será necessariamente melhor, mas, sim, outro (REIS, 2006, p. 210), bem como que algo de importante para o povo poderá ser perdido e substituído por algo que restrinja sua vida.

Em síntese, de um lado, uma posição que valoriza a universalização e a certeza de um futuro reluzente, em muito superior ao passado de trevas e de obscurantismo em que se vivia; de outro, uma posição de desconfiança e de valorização do particular, do povo, da nação e de um passado que poderia ser admirável. Positivismo e historicismo em frontal oposição, com correspondência em dois modelos metodológicos e de ação social, que estão na base da construção das ciências humanas e, por que não, das ciências da Educação, a saber: a sociologia de Durkheim e a compreensão empática de Dilthey. Sobre a sociologia de Durkheim, aparentemente o conhecimento é mais claro e abrangente. Todavia, sobre a compreensão empática em Dilthey, melhor buscar entendimento em Reis (2006, p. 237):

A história se encontra com a vida pela compreensão. A historicidade do homem está ligada à vida sociocultural. A individualidade concreta do homem não apaga sua condição social e cultural. O indivíduo não é isolado e só. $\mathrm{O}$ homem tem uma natureza aberta e comunicativa. A compreensão empática (verstehen) é a própria natureza humana. A história é constante mudança, típica e única. O que permanece em todas as épocas e sociedades é a expressão, a compreensão, a comunicação entre os homens diferentes. Para [Dilthey] o homem é a 'experiência vivida', que cria, que se expressa, que se comunica, que compreende e se deixa compreender. E que se inquieta com sua existência. A verdade é o próprio processo histórico, em que a vida se expressa e é compreendida, e não uma proposição abstrata e atemporal. Dilthey não prescreve uma finalidade para a História. O humano está por toda parte em realização. [Dilthey] defende a liberdade sem sistemas.

De fato, ao não prescrever um sentido único e inevitável para a História, por meio da defesa de um estado de abertura para a compreensão da historicidade da vivência comunicativa, Dilthey contribui para um afastamento de uma mentalidade que pode ser tornar base para posições fundamentalistas, portadoras de verdades universais, abstratas, aplicáveis a todas as pessoas e lugares de modo indistinto, sem respeito às diferenças.

Nessa direção, a ideia de um homem novo que rompe com seu passado, descontextualizando-se, é tomada como uma impossibilidade, mas, também, a ideia que o sentido da História poderia ser buscado, por exemplo, na ordem cristã, na razão progressista hegeliana, no estado positivo comtiano, no comunismo etc. não encontra sustentação possível, dada as contingências postas pelo processo em aberto que é a vivência em sua historicidade. Em outras palavras, a vida, não poucas vezes, pode teimar em desobedecer a razões que a ela possam ser imputadas!

\section{As tramas da alteridade e da identidade}

Verifique-se, inicialmente, a ideia de perfectibilidade contida na compreensão da natureza humana em Jean-Jacques Rousseau (1712-1778), conforme apresentado por Ferry 
(2007): a faculdade de se aperfeiçoar ao longo da vida. O animal, por seu turno, seria perfeito de imediato, desde o nascimento. Assim, o animal estaria preso a sua programação, enquanto o homem será definido por sua capacidade de se libertar do programa do instinto natural, com possibilidade de ter uma história, porém, uma história sempre indefinida!

Eis aí uma ideia fundamental de natureza humana, largamente difundida, e que animou e ainda esta a animar, uma série multifacetada de crenças presentes em um sem número de concepções de mundo, de ideologias, de políticas de Estado etc. Muitas delas, porém, em desacordo com o princípio geral de Rousseau, pois que elas almejam estabelecer uma programação para o indefinido, uma finalidade ou, pelo menos, discursam sobre a implacabilidade de um destino, tal como o Sacro Império, o Estado Positivo, o $3^{\circ}$. Reich, os estados novos ou mesmo a ideia de socialismo ou barbárie...

No que diz respeito à natureza humana, em contraponto, tome-se a ideia de Dilthey, não tão largamente disseminada, mas que parece especialmente útil aos propósitos desse texto, conforme exposto em Reis (2006, p. 237-8)

[...] o que há de absoluto no homem, o que o diferencia da natureza, é a possibilidade que ele tem, em sua experiência vivida, de se expressar e se fazer compreender pelo outro. Por mais diferentes que sejam os homens em suas sociedades, culturas e épocas, subsiste em todos a possibilidade de expressão e da compreensão recíproca. O reino do espírito, o mundo histórico, é um mundo de sentido, em que a comunicação é possível e se realiza. Quanto maior é a diferença entre os homens, mais necessária a comunicação se torna e mais intensa é a compreensão do outro. A vida cria linguagens múltiplas e decifráveis - escritas, orais iconográficas, arquiteturais, artesanais, tecnológicas, quantitativas, simbólicas, alimentares, rituais, sagradas, cromáticas etc. Enfim, o mundo do espírito é um mundo de linguagens, que criam sentidos, mensagens, que são decifráveis e compreensíveis (Grifos meus).

A propósito, no mundo atual - que é enormemente conectado do ponto de vista das trocas comerciais e das possibilidades de circulação de pessoas, o que tem significado, por vezes, ações de reconhecimento recíproco e, em outras oportunidades, práticas de xenofobia - a ideia de que "[...] quanto maior é a diferença entre os homens mais necessária a comunicação se torna" parece de grande atualidade. Todavia, nesse sentido, antes de avançar, parece oportuno e pertinente trazer ainda à lembrança algumas das ideias de um imigrante búlgaro em solo francês, Tzvetan Todorov (1939- ), sobretudo a partir das reflexões que ele pôde fazer sobre a conquista da América, em especial no que se refere à conquista espanhola, na qual elementos de identidade (semelhança) e de alteridade (diferença) cultural possibilitaram melhor compreensão de um intricado processo de prevalência de um povo sobre outro, do espanhol sobre o asteca, o maia, o inca, o indígena, dado que para os últimos, segundo o autor, a noção de tempo cíclico, presente em seus calendários e, portanto, em sua noção de tempo, prendia-os a ideia de repetição, dificultando sua compreensão do novo.

De outro lado, os espanhóis, ávidos pelo novo, pelas vantagens imediatas que ele poderia dar, compreendiam melhor o que fazer naquele novo mundo, a saber: ajustá-lo ao seu mundo histórico particular, podendo, no presente, nele habitar e governar, por meio de um processo de aculturação, no qual o Outro poderia ter lugar, mediante a incorporação dos elementos culturais alienígenas. Observa-se, desse modo, que a comunicação foi possível, porém, mediante a manutenção de uma relação de superioridade do EU, do espanhol, do cristão, sobre o OUTRO, o indígena, o asteca, o maia, o inca etc. 
Nessa direção, parece importante trazer ainda outras ideias para o centro das atenções, novamente de um "imigrante" (ainda que entre aspas), o filósofo judeu Martin Buber (1868-1965), nascido em Viena, Áustria e que, em 1938, passou a lecionar em Jerusalém, Israel. Para Buber, há duas dimensões importantes em relação ao sujeito, a do Eu-Tu (relação) e do Eu-Isso (experiência). Von Zuben (1985) sintetizou as principais ideias de Buber, sendo que a seguir serão trazidas àquelas que se aproximam melhor dos propósitos do presente texto. Assim, inicialmente, há um elemento da autobiografia de Buber que é revelador da problemática que ele enfrentaria em sua vida, pois que assinala sua ideia de desencontro (Vergegnung), entendida como falha do encontro entre dois seres e que orienta sua busca, um tanto quanto utópica, da possibilidade de uma conversação autêntica. Narra Buber:

A casa onde moravam meus avós tinha um grande átrio com um balcão de madeira em sua volta em cada andar. Vejo-me ainda, quando não havia completado 4 anos, em pé junto aquele balcão, na companhia de uma menina alguns anos mais velha que eu e que, a pedido de minha avó, tomava conta de mim. Nós dois estávamos apoiados na balaustrada. Não me lembro de ter falado de minha mãe com minha companheira. No entanto, ouço-a ainda, falar-me: "Não, ela não voltará jamais". Lembrome ter permanecido em silêncio e também não tive dúvida sobre a veracidade daquelas palavras. Elas calaram profundamente em mim, a cada ano que passava sempre mais profundamente; e aproximadamente dez anos mais tarde comecei a perceber que ela não dizia respeito somente a minha pessoa, mas a todo ser humano. Mais tarde a palavra "desencontro" (Vergegnung) que havia cunhado para mim, significou a falha de um encontro entre dois seres. E, quando 20 anos mais tarde revi minha mãe que tinha vindo de longe para visitar a mim, minha mulher e meus filhos, não pude fixar seus olhos, sempre surpreendentemente belos, sem ouvir ressoar em meus ouvidos esta palavra "desencontro" como endereçado a mim. Creio que tudo o que, em seguida eu aprendi a conhecer sobre o autêntico encontro, teve sua origem naquele instante, lá em cima naquele balcão [Autobiografia: Minha mãe] (Citado em Von Zuben, 1985, p.1).

No esforço de designar melhor a ideia de conversação autêntica, Buber explicita que o rompimento do homem com sua solidão é apenas possível quando reconhece no outro, com toda sua alteridade (diferença), como si mesmo, como Homem. Para Von Zuben (1985, p. 2):

Segundo [Buber], o homem, há décadas, vem assistindo impotente a prepotência do princípio político (a supremacia avassaladora do Estado), sobre o princípio social e ético. Neste estado de coisas este homem, cada um de nós, concretamente - sente ameaçadas sua autonomia e as possibilidades de auto-afirmação de sua liberdade. Esta época se pautou pela ideologia do progresso, acreditou demasiadamente nas possibilidades pretensamente ilimitadas da razão, da ciência e da técnica. No entanto, este homem já percebeu a falácia destas pretensões. Ele se sente abalado, uma vez que lhe foi inculcado que o mundo sem a ciência é inseguro. "Durante sua passagem pelo caminho terreno, o homem foi aumentando em ritmo crescente o que se costuma denominar de seu poder sobre a natureza, e conduzir, de triunfo em triunfo, o que se deliberou denominar de a criação de seu espírito. Entretanto, enquanto passava por crise após crise começou a sentir, cada vez mais profundamente, a fragilidade de sua grandeza e, em horas de 
clarividência, conseguiu entender que, apesar de tudo o que se costuma chamar de progresso da humanidade, não caminha absolutamente por uma estrada aplanada, mas é obrigada a trilhar, pé ante pé, uma estreita cumeada entre abismo. O homem se sente, de certo modo, aliviado do jugo da ciência e livre para, finalmente, reencontrar a vida prosaica de seus sentimentos, suas emoções de seu desejo. Este homem já percebeu a insuficiência da linguagem científica na interpretação das dimensões fundamentais da existência humana. Ele está consciente de que, nas palavras de Buber, "não se pode viver sem o Isso, mas quem vive só com o Isso não é homem".

Para além dessa crítica ao mundo contemporâneo, é interessante observar que para Buber o questionamento sobre si mesmo é mais do que um simples exercício intelectual é um ato vital, no qual está em jogo a própria existência humana. Para ele o "[...] importante é que, para cada um dos dois homens, o outro aconteça como este outro determinado; que cada um dos dois se torne consciente do outro de tal forma que precisamente por isso assuma para com ele um comportamento, que não o considere e não o trate como seu objeto, mas como seu parceiro em um acontecimento de vida" (Citado em Von Zuben, 1985, p. 4).

Segundo Von Zuben, no intuito de apresentar os caminhos para o estabelecimento de uma conversação autêntica, Buber explicitou três necessidades que, examinadas nos dias de hoje, revelam o caráter dificílimo de suas ideais, a saber: $1^{\circ}$. os sujeitos apresentarem-se sem reservas, sem preocupações com a imagem que querem apresentar ao interlocutor; $2^{\circ}$. "tornar o outro presente", sem transformá-lo em objeto; $3^{\circ}$ evitar a tendência a imposição, tendo, em contrapartida um postura de abertura. Sobre o terceiro aspecto, é interessante observar que para Buber, a propaganda é um exemplo claro de imposição e a educação de abertura. Para Buber, há dois princípios para a existência humana, o monológico, referente ao mundo do Isso e o dialógico, referente ao mundo do $\mathrm{Tu}$, a saber:

De todas as esferas onde se realizam tais relações, a esfera do interhumano é a mais genuína. Esta relação entre humanos se manifestou como uma convergência que implica presença e participação mútuas. A ação que se desenvolve é recíproca. A participação conjunta resguarda a alteridade a individualidade dos participantes na relação. Embora a relação Eu-Tu não se reduza à esfera do humano é nesta que a reciprocidade das ações atinge o grau mais elevado. Na relação dialógica a palavra da invocação recebe a resposta. É neste face a face que o Eu e o Tu se presentificam. A presença aí passa a ser justamente o momento da reciprocidade. Esta presença recíproca é a garantia da alteridade preservada. Na atitude Eu-Tu não me relaciono com o outro através de qualquer meio, como a sua função social, mero papel que encobriria sua autêntica singularidade enquanto ser humano. É todo o ser que está presente. "Todo meio é obstáculo" afirma Buber. O Tu se dá na presença e não na representação de um Eu. A relação é uma ação imediata que acontece entre o Eu e o outro. Não há supremacia de um sobre o outro. $\mathrm{O}$ outro, quando é um Tu, não pode ser considerado como um objeto para minha observação, para meu uso. Se isso ocorrer já deixou de ser um Tu tornando-se um Isso, este sim objeto de meu uso, de minha experimentação (Von Zuben, 1985, p. 5).

Em síntese, a possibilidade de ter uma História sempre indefinida, em Rousseau; a compressão empática em Dilthey; as dificuldades de comunicação apontadas em Todorov 
e a busca de uma conversação autêntica em Buber, tomadas em seu conjunto, contribuem para a reflexão no âmbito da historiografia, em especial sobre a relação entre memória e história e sobre a utilidade da História Oral nas pesquisas sobre o ensino secundário.

\section{A contribuição da História Oral na pesquisa sobre o ensino secundário}

Nas duas últimas décadas, os membros do Núcleo de Estudos e Pesquisas em História e Historiografia da Educação da Universidade Federal de Uberlândia têm se dedicado ao processo de levantamento e de catalogação de fontes de interesse para a História da Educação na região do Triângulo Mineiro e Alto Paranaíba, com trabalhos junto aos acervos públicos, das cidades envolvidas (Uberlândia, Uberaba, Araguari, Patos de Minas, Patrocínio etc.), bem como nos acervos de diversas instituições escolares ou mesmos naquelas já extintas, cujos acervos estão depositados nos arquivos das superintendências de ensino. Além disso, também têm sido importantes os levantamentos realizados junto aos acervos particulares, de pessoas que frequentaram as instituições escolares das cidades pesquisas na qualidade de professores, administradores ou de alunos.

Assim, no desdobramento desses levantamentos de fontes, ganhou relevo nas atividades do NEPHE, a investigação histórico-educacional acerca das instituições escolares mais antigas existentes na referida região, para o que concorreu positivamente o conhecimento do farto acervo de fontes documentais e iconográficas levantadas, mas, também com grande importância, as possibilidades concretas de cotejamento daquilo que se pôde ler nos documentos, o que incluía também a imprensa local, com os diversos depoimentos que foram possíveis recolher nas diferentes investigações realizadas.

Ao lado desse empreendimento que envolvia, sobretudo, o trabalho de historiar a escola na região, em especial seus grupos escolares e ginásios e, secundariamente, o ensino superior, também ganhou terreno o estudo sobre o desenvolvimento da formação de professores, por meio da dedicação aos processos sócio-históricos operados nas Escolas Normais que, a semelhança do país, também proliferou na região. Neste último caso, notadamente, devido ao interesse pela História Disciplinar da História da Educação, buscou-se o conhecimento mais profundo dos lugares em que a disciplina se efetivou nas grades curriculares e nas atividades escolares desenvolvidas nas Escolas Normais. Aqui, novamente, ao lado de farta documentação e de razoável iconografia, buscou-se somar a riqueza dos depoimentos que foi possível recolher ao longo das pesquisas.

Por fim, também recentemente, ao trabalhar em parceria com pesquisadores vinculados a três outras diferentes instituições universitárias, no Observatório de Cultura Escolar, foi possível verificar a fertilidade com a qual puderam conjugar-se nas investigações documentos de ordem manuscrita, impressa e iconográfica aos depoimentos que foi possível conseguir junto às pessoas envolvidas com a vida das instituições escolares examinadas.

Ao considerar essas experiências de pesquisa, parece importante assinalar que os elementos biográficos das pessoas que deram vida àquelas instituições que habitaram em determinada época, contribuiu de modo marcante, sobretudo, quando se acumularam diversas memórias sobre o mesmo objeto e período histórico, para que os pesquisadores pudessem compreender melhor aquilo que identificava as instituições nas cidades nas quais as escolas estavam sediadas, seus elementos constantes, mas, também, os conflitantes, pois, ao lado de uma série de discursos por vezes laudatórios acerca das instituições, colocaram-se também, em diversas oportunidades, posições de desapreço e até mesmo de profundo ressentimento com a vida escolar. Elementos esses que, cotejados, fomentavam 
nos pesquisadores o exame dos aspectos contraditórios dos lugares em que se buscava instruir e moldar crianças e jovens nas diversas cidades e épocas pesquisadas.

Nesse sentido, o esforço de compreensão por parte dos entrevistadores era fundamental, pois, em relação ao passado, ou seja, ao mundo histórico que não poderiam habitar, os pesquisadores são "estrangeiros" que pelas dificuldades da própria situação podem não perceber as sutilezas das formas de viver em circunstâncias que muitas vezes já não existem, pois, o que é de grande facilidade na atualidade, tal como, adquirir um livro, fazer uma viagem, buscar informações sobre um ou outro assunto, voltar para casa após um dia de escola, não se processava desse modo no passado das pessoas que habitavam as cidades à época de sua escolarização.

Deste modo, as vozes que se consegue buscar de pessoas que viveram momentos passados da vida escolar e da cidade que habitavam são elementos que não podem ser negligenciados para a construção do entendimento das formas concretas tomadas por uma série de mecanismos construídos em acordo com determinadas finalidades prescritas mas que se articulavam à vida de maneira imprevista e produziam história, mas não uma história linear, em correspondência com um projeto fechado e mensurável, mas, sim, à semelhança do que preconizava Rousseau, de uma história sempre indefinida.

A título de exemplo, apresentam-se, a seguir, alguns resultados de pesquisa desenvolvida sobre a vida escolar em uma instituição de ensino secundário, o Gymnásio Mineiro de Uberlândia (GMU), no período compreendido entre 1929 e 1950, na qual fica evidenciada a riqueza interpretativa alcançada no cotejamento de documentação manuscrita e imprensa, iconografia e depoimentos colhidos junto a ex-alunos principalmente, mas, também junto a professores e administradores, o que pode ser examinado em Gatti, 2010.

Nesse sentido, uma característica marcante da GMU era sua função de centro social, esportivo e cultural da cidade, em especial no que se refere ao que era preconizado como legitimo a época pelos poderes constituídos. Em Uberlândia, à semelhança do que ocorria por todo país, as festas cívicas realizadas pelas escolas tinham participação ativa de seus alunos, com extensas programações, discursos, apresentações artísticas e esportivas.

O Gymnásio era o local onde os alunos se encontravam e se confraternizavam, não só entre eles, mas também, contando com a presença de colegas de outros estabelecimentos de ensino da cidade e da região que participavam dos eventos culturais e esportivos promovidos, muitas vezes, pelo próprio GMU. Segundo consta do depoimento do Dr. Rondon Pacheco, os "[...] alunos participavam muito das festividades, havia uma integração muito grande e eram muito unidos" (PACHECO, 2000). As festas cívicas davam grande visibilidade às escolas, particularmente ao GMU, como uma forma de mostrarem e reafirmarem, perante a sociedade, suas ideias e valores, importantes na constituição da cultura da cidade.

O Sete de Setembro era comemorado na cidade com a mobilização não só de Gymnásio, mas também de muitas outras escolas da cidade. Nesse sentido, Dona Isolina Cupertino que foi aluna do colégio entre 1939 e 1942, relembra que a Semana da Pátria era a data mais esperada por todos os alunos e, sobretudo pelas pessoas da cidade, pois da parte dos alunos, existia uma expectativa enorme pela responsabilidade de representar os ideais de civismo e respeito à Pátria. Um grande desfile era realizado pelas principais ruas da cidade e, segundo relato da Profa. Sônia Maria Miranda Vieira, que foi professora no colégio entre 1949 e 1971, os colégios competiam a fim de realizarem o melhor desfile. 
Figura 1 - Desfile Cívico do Sete de Setembro pelo Colégio Estadual de Uberlândia. s/d.

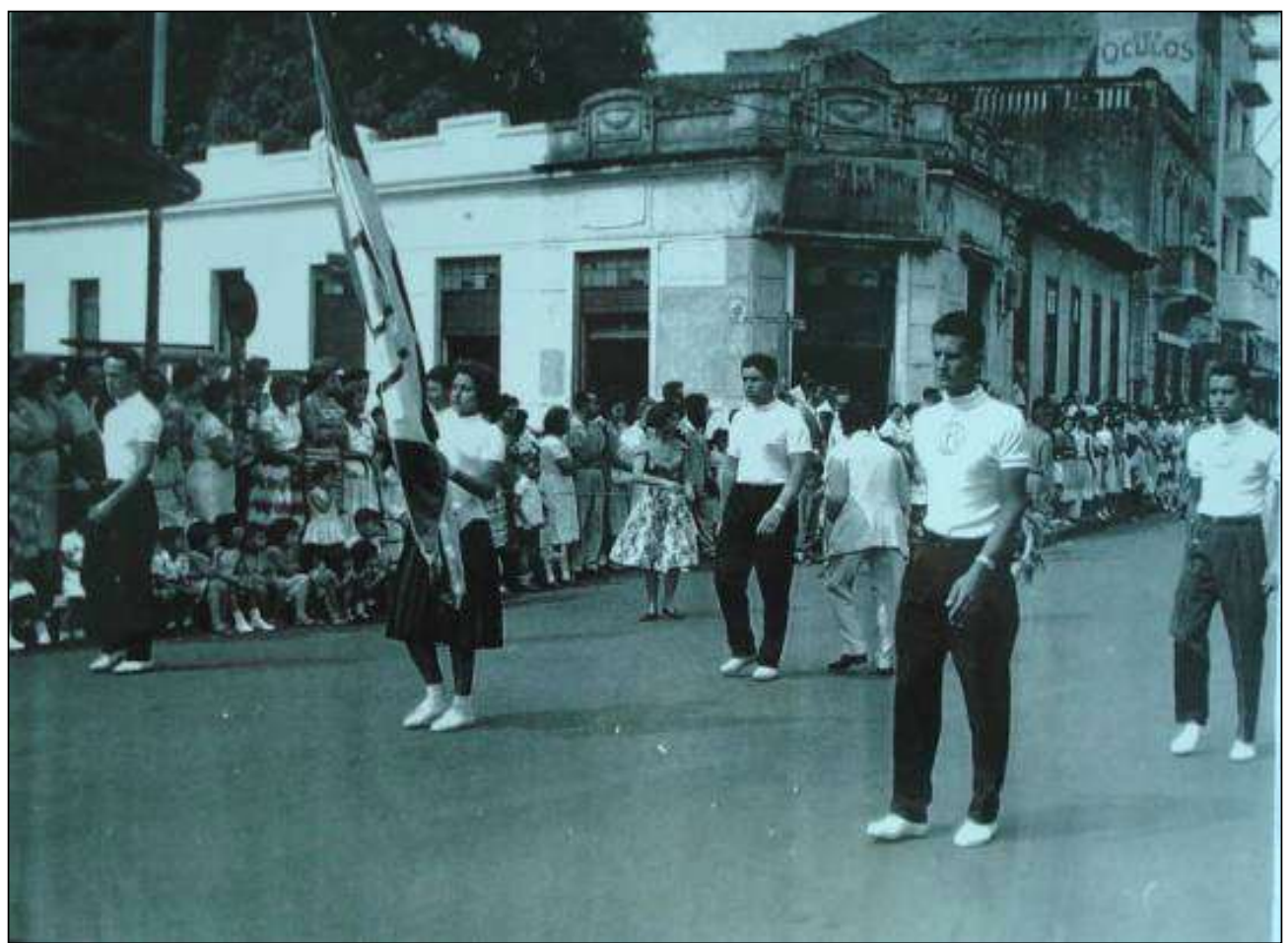

Fonte: Acervo da Escola Estadual de Uberlândia.

Figura 2 - Fanfarra do Colégio Estadual de Uberlândia na década de 1940

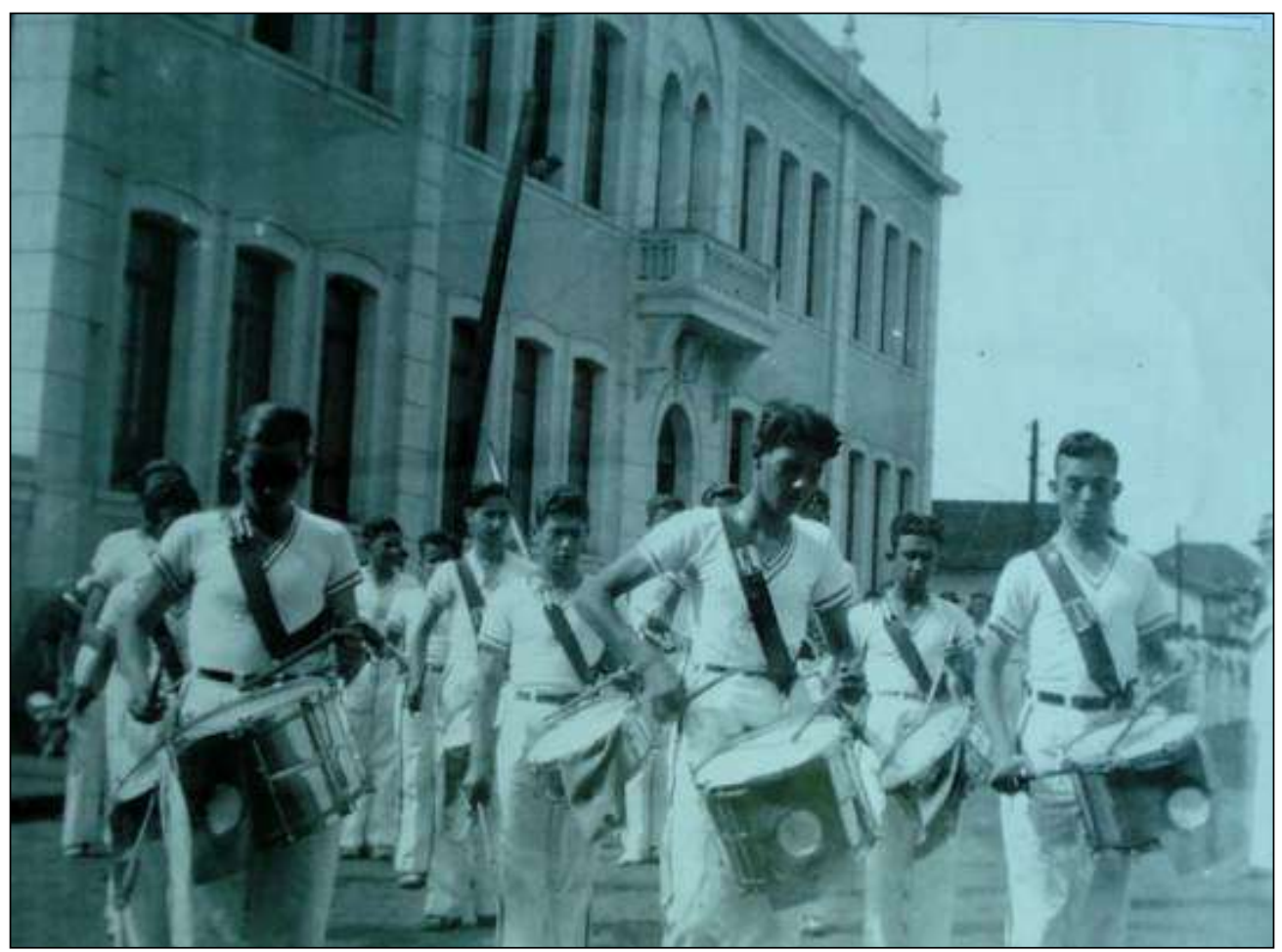

Fonte: Acervo da Escola Estadual de Uberlândia 
Nessa direção, o Sr. Luiz Alberto Garcia, ex-aluno do GMU, relembra com nostalgia as festividades que lá aconteciam, destacando, inicialmente, as festas juninas.

Tinham as festas juninas que eram feitas num galpão. O Gymnásio Mineiro, naquela ocasião, tinha dois galpões, eu não sei se hoje ainda tem. Tinha um de basquete que faziam as festas juninas que era uma quadra semi-coberta que tinham festas ali, bailes muito bonitos. E tinha um salão no primeiro andar que era um salão que faziam as festas de formatura, os bailes eram feitos ali. Isso eu guardo comigo com muita lembrança, com muito amor. A sociedade toda participava. O Sete de Setembro, por exemplo, era interessante, não só o Gymnásio Mineiro, mas todas as escolas de Uberlândia começavam uns quinze dias úteis antes do Sete de Setembro, do Quinze de Novembro que tinha desfile na cidade, e começavam a preparar, em todas as ruas durante o dia saiam marchando em volta do quarteirão, treinando para o Sete de Setembro. Era uma festa que todas as escolas de Uberlândia faziam, inclusive até o Colégio das Freiras usavam a banda do Colégio Mineiro, o Estadual, para tocar no Colégio das Freiras, porque as meninas não tocavam. E os alunos saiam uniformizados. Era um uniforme caqui. Tinha um uniforme caqui, uniforme amarelo, era todo mundo uniformizado (GARCIA, 2000).

A imprensa local, por seu turno, também dava amplo destaque às festividades cívicas realizadas na cidade, conforme se pode ler em reportagem do jornal "O Repórter" de 5 de setembro de 1942, na qual se destacava o papel central da instituição escolar em exame:

Cabe ao Gymnásio Mineiro, sem duvida destacada referencia quanto ao relevo da parte de seu programa nas comemorações da Semana da Pátria. Com efeito, aquele reputado educandário oficial, com a orientação didática que lhe imprimiu seu atual Reitor, o infatigável educador professor Oswaldo Vieira Gonçalves, iniciou desde o dia primeiro as suas expansões de patriotismo no período destinado a evocação do nosso passado e das nossas glórias, na fundação da nacionalidade livre com a resolução de Pedro I as margens históricas do Ipiranga. [...] Foi este itinerário percorrido pelos condutores da Tocha, símbolo de fé e de devotamento do coração da mocidade a grande pátria: - partida do Gymnásio, pela Avenida Cipriano Del Fávero até a esquina da Rua Getúlio Vargas, por esta à Avenida João Pinheiro, desta à Avenida João Pessoa, Avenida Floriano Peixoto, praça Cel. Carneiro, Rua Tiradentes, Vigário Dantas e novamente o Gymnásio. [...] Os números executados pelas alunas, que foram treinadas e receberam instrução física da competente e dedicada professora Dona Luiza Ribeiro Miranda, causaram ótima impressão na assistência, pela segurança e magnífica execução, recebendo fortes aplausos.

O mesmo jornal, “O Repórter", em nova reportagem sobre a Semana da Pátria, datada de 12 de setembro de 1942, elogiava as magníficas demonstrações de civismo efetivadas na cidade:

Foi uma festa singular esplendor a concentração da juventude uberlandense no dia 5 corrente, na Praça Benedito Valares, ponto escolhido de partida para o desfile em conjunto pelas ruas da cidade. Ao ritmo dos tambores, ao toque das marchas pelas bandas de corneta, a mocidade sadia marchou conduzindo triunfalmente dezenas de bandeiras brasileiras. $\mathrm{Na}$ apoteose deslumbrante e emocional da Pátria, que 
ultrajada ergue-se exigindo a revide, os colegiais significavam bem, em sua sadia vibração cívica, a alma do Brasil consciente da vitória e destemido as provocações dos bárbaros sequiosos de demolir, no mundo, a milenar civilização que construiu monumentos imperecíveis de cultura, e de que nasceram as nações livres no fulgor das democracias. Nunca assistimos, como na hebdomada votiva de comemorações históricas na nossa nação maravilhosa, espetáculo de tão empolgante beleza, índice cristalino que nos deu a visão do trabalho de brasilidade que se pratica em nossos educandários. Nem se podia selecionar ou distinguir qual estabelecimento que melhor se preparou para essa jornada de culto ao Brasil, pois em todos percebia-se no conjunto e nos detalhes, o Maximo capricho na organização dos seus quadros discentes. Rapazes e moças, com o mesmo garbo e uniformidade de marcha deixavam transparecer a sinceridade que os inspirava naquela cerimônia de nobreza impar. E os aplausos do público numeroso e alegre, nas sacadas dos prédios e de um lado e de outro nos passeios das ruas anunciadas para o itinerário do desfile escolar, diziam bem alto da impressão cansada por essa parada das nossas casas de ensino no animo de todos os que tiveram a gravíssima felicidade de presencia-la. Cabem nesta noticia as melhores felicitações aos diretores, professores e alunos de estabelecimentos que figuram nessa festa, cujo profundo sentido espiritual enaltece ainda mais as tradições seculares de Minas Gerais e do Brasil.

As festas cívicas movimentavam a cidade, sendo um espetáculo à parte, motivo de orgulho de alunos, professores, diretores e sociedade. Tais festas traziam visibilidade às instituições de ensino, bem como fazia da escola um instrumento para perpetuar os projetos de civilidade, ordem e progresso de então. Para o Sr. Paulo Ferolla, ex-aluno do Gymnásio nos anos quarenta do Séc. XX, e prefeito de Uberlândia no período de 1993 a 1996, o envolvimento dos alunos em atividades esportivas e culturais era destacado, pois

Havia uma convocação muito grande. E inclusive era um período em que as oportunidades de lazer eram poucas, muito restritas, nem tinha área de lazer, o colégio tinha quadra de basquete, voleibol, então nós jovens toda convocação que nós tínhamos para participar de qualquer tipo de festividade ou de prática esportiva havia uma adesão muito grande por parte dos estudantes. E éramos até estimulados, nós tínhamos um professor de educação física que era muito bom, naquela época nós tínhamos educação física permanentemente. Então é como eu falei as oportunidades não eram muitas então nós nos apegávamos aquelas que tinham no colégio. E havia inclusive disputa entre os colégios, nós tínhamos disputas esportivas entre os colégios não apenas aqui de Uberlândia como saíamos, nós íamos em Araguari, íamos a Uberaba, disputar atividades esportivas (FEROLLA, 2000).

A prática esportiva e os eventos culturais no caso do Gymnásio eram uma opção de lazer, porém tornam-se o elemento cultural de boa parte de uma sociedade, pois que essa se agregava, socializava-se e interagia por meio de tais manifestações. Além disso, o espaço do antigo GMU foi local onde se realizavam várias atividades culturais, brincadeiras de domingo e teatro. A Profa. Sônia Borges Miranda Vieira relatou que as peças de teatro encenadas no colégio eram variadas, tais como: "História da Carochinha", "Maria Papo do Engenho", "Príncipe Cirilo". Fazíamos aquela comemoração, um histórico a caráter; os alunos bem vestidos, porque as mães faziam questão de confeccionar as roupas. "Tinham alunos de séries mais avançadas que tocavam música, outros cantavam ou então recitavam poesias" (VIEIRA, 1999). 
Em complemento a apresentações como estas, havia ainda peças mais elaboradas de autores como Shakeaspeare. Maria Oranides Crosara pertencente a uma família tradicional da cidade e que estudou no colégio entre 1937 e 1942, ressaltou que essas atividades sempre contavam com grande participação tanto de alunos quanto dos professores (CROSARA, 2000), e na medida do possível, essas apresentações eram estendidas à comunidade, pois o teatro era pequeno. Moacir Franco, conhecido cantor brasileiro, relembrou, em entrevista ao jornal O Correio, por ocasião do tombamento da escola como patrimônio cultural da cidade, que a sua primeira oportunidade como cantor aconteceu no colégio. Relembra ele, "Em Uberlândia, cantei pela primeira em uma orquestra. Era um baile de formatura [...]. Consegui essa vaga porque pintei as estantes da escola. Era num salão nobre, com piano" (FRANCO, 2005).

\section{Considerações finais}

Parece importante estar com nossos antepassados por meio de suas memórias, de seus relatos pessoais, de suas biografias, com o exame dos acontecimentos que viveram, com a percepção que puderam ter daquilo que passou. Metodologicamente, o recurso a História Oral contribui para dar vida a acontecimentos que, por vezes, são relatados nos documentos manuscritos, escritos, iconográficos e videográficos que restam do passado, nesse caso, em situações do mundo histórico-educacional, com o exame de questões que transcendem as regras determinadas pelo Estado, pela Igreja e pela sociedade civil, mas que estão contidas na forma particular como docentes e discentes efetivaram suas práticas, sua vida cotidiana, servindo-se dos recursos próprios e dos interesses que possuíam a época.

Por isso, as imagens do lugar são sempre úteis e ajudam a nos colocar na cena, ainda que as escolhas daquilo que se registra sejam quase sempre administradas pelo poder estabelecido e pelos interesses de propaganda. Todavia, ao cotejar documentos que restaram do passado e as imagens que se produziram naquela época, com aquilo que o sujeito ou que os sujeitos puderam memorizar por meio da recolha de valiosos depoimentos tem sido algo que possibilita uma análise mais abrangente, na direção de cotejar às finalidades estabelecidas à realidade das práticas escolares vivenciadas, no caso particular da presente reflexão, no âmbito do ensino secundário brasileiro.

\section{Referências}

BUBER, Martin. Eu e Tu. Tradução, introdução e notas de Newton Aquiles Von Zuben. $9^{a}$. edição. São Paulo: Centauro. 2004. 152p.

DILTHEY, Wilhelm. II. A compreensão de outras pessoas e as suas manifestações vitais. In: A construção do mundo histórico nas ciências humanas. Tradução de Marco Casanova. Clássicos UNESP. São Paulo: Editora UNESP. 2010. 346p.

FERRY, Luc. Aprender a viver: filosofia para os novos tempos. Tradução de Vera Lucia dos Reis. Rio de Janeiro: Objetiva. 2007. 302p.

GATTI, Giseli Cristina do Vale. Tempo de Cidade, Lugar de Escola: dimensões do ensino secundário no Gymnásio Mineiro Uberlândia (1929-1950). Tese de Doutorado. Programa de Pós-Graduação em Educação da Universidade Federal de Uberlândia. 2010.

JULIA, Dominique. Educação. In: BURGUIÈRE, André (Org.) Dicionário das Ciências Históricas. Tradução de Henrique de Araujo Mesquita. Rio de Janeiro: Imago Ed. 1993. p. 264-74. 
REIS, José Carlos Reis. Dilthey e o historicismo, a redescoberta da história. In: História \& Teoria: historicismo, modernidade, temporalidade e verdade. $3^{\text {a }}$. ed. Rio de Janeiro: Editora da FGV. 2006. p. 207-46.

TODOROV, Tzvetan. A conquista da América: a questão do outro. Tradução de Beatriz Perrone Moisés. $2^{\mathrm{a}}$. ed. São Paulo: Martins Fontes. 1988. 263p.

VON ZUBEN, Newton Aquiles. Martin Buber e a Nostalgia de um Mundo Novo. Reflexão. Pontifícia Universidade Católica de Campinas. n. 32. maio/agosto 1985. Disponível em http://www.fae.unicamp.br/vonzuben/nostalg.html. Acesso: 20 jun. 2012.

\section{Jornais de época}

O Repórter - 05/09/42

O Repórter - 12/09/42

\section{Depoimentos}

Isolina Cupertino - Depoimentos colhidos por Giseli C. V. Gatti, em 2000 e em 2008.

Luiz Alberto Garcia - Depoimento colhido por Giseli C. V. Gatti, em 2000.

Maria Oranides Crosara - Depoimento colhido por Giseli C. V. Gatti, em 2000.

Moacir Franco - Depoimento colhido por Giseli C. V. Gatti, em 2000 e concedido ao jornal O Correio, com publicação em 22/06/2005.

Sônia Borges Miranda Vieira - Depoimento colhido por Geraldo Inácio Filho, em 1999.

Paulo Ferolla - Depoimento colhido por Giseli C. V. Gatti, em 2000.

Rondon Pacheco - Depoimento colhido por Giseli C. V. Gatti, em 2000 e pelo Museu da Pessoa/Instituto Algar, s/d.

Recebido em janeiro-13

Aprovado em maio-13

Notas

\footnotetext{
${ }^{1}$ Versão modificada de trabalho originalmente apresentado em sessão de comunicação coordenada intitulada "O ensino Secundário no Brasil Republicano: perspectivas analíticas e instituições", organizada pela Profa. Dra. Eurize Caldas Pessanha, da Universidade Federal de Mato Grosso do Sul (UFMS), no interior das atividades do VII Congresso Brasileiro de História da Educação, realizado entre os dias 20 e 23 de maio de 2013, em Cuiabá, Mato Grosso, Brasil.

${ }^{2}$ Doutor em Educação pela Pontifícia Universidade Católica de Uberlândia (PUC-SP), com estágio de pósdoutorado concluído na Faculdade de Educação da Universidade de São Paulo (FEUSP). Professor permanente do Programa de Pós-Graduação em Educação da Universidade Federal de Uberlândia (UFU). Email: degatti@ufu.br

${ }^{3}$ Doutora em Educação, com estágio de pós-doutorado concluído na Universidade Federal de Uberlândia (UFU). Professora permanente do Programa de Pós-Graduação em Educação da Universidade de Uberaba (UNIUBE). Professora colaboradora do Programa de Pós-Graduação em Educação da UFU. E-mail: giseli.vale.gatti@gmail.com
} 